\title{
Investigation of the Granger Causal Relationship Between Macroeconomic Variables and Stock Prices in Kenya
}

\author{
Mohammed Mustapha Wasseja ${ }^{1}$, Elizabeth Njoroge ${ }^{1}$, Samwel N. Mwenda ${ }^{2}$ \\ ${ }^{1}$ Department of Business Administration, Chuka University,Chuka, Kenya \\ ${ }^{2}$ ICT Department, Kenya National Bureau of Statistics, Nairobi ,Kenya \\ Email address: \\ muswaseja@gmail.com (M. M. Wasseja), elizawn@gmail.com (E. Njoroge), smwenda@knbs.or.ke (S. N. Mwenda)
}

\section{To cite this article:}

Mohammed Mustapha Wasseja, Elizabeth Njoroge, Samwel N. Mwenda. Investigation of the Granger Causal Relationship Between Macroeconomic Variables and Stock Prices in Kenya. International Journal of Business and Economics Research.

Vol. 4, No. 3, 2015, pp. 98-108. doi: 10.11648/j.ijber.20150403.13

\begin{abstract}
The aim of this paper was to analyze the causal relationship between macroeconomic variables and stock prices in the VAR(Vector Autoregressive) modeling framework using secondary time series annual data from 1980 to 2012. Sim's causality test based on Granger definition of causality was used to test the causality relationship while OLS (Ordinary Least Squares) is used to test for any significant relationship. According to Granger causality test results, it is evident that movement in the macroeconomic variables had no significant effect on stock prices except for inflation rate; exchange rate and change in stock prices also seem to be an insignificant factor explaining part of the movement in the macroeconomic variables except for market interest rates. Also, the regression test result shows that all the macroeconomic variables are jointly significant in explaining the variations in stock prices. Hence, the findings imply that the causality between macroeconomic variables and stock prices runs unilaterally or entirely in one direction from inflation rate and exchange rate to stock prices and from stock prices to market interest rates. Thus, there is evidence to show that inflation rate and exchange rate are the cause of movement on stock prices and stock prices are the cause of movement of interest rates in Kenya.
\end{abstract}

Keywords: Granger Causality, Stock Prices, Vector Autoregressive

\section{Introduction}

\subsection{Background Information}

Stock market is a market that deals with the exchange of securities issued by publicly quoted companies and the government. The market is a crucial institution in an economy which greatly determines and indicates the performance of an economy. The nature and the state of a stock market is of great concern to the government, investors and generally all the stake holders.

In an emerging economy, it is generally agreed that stock market under general equilibrium must play a very important role in collecting and allocating funds in an efficient manner. They are required to meet at least two basic requirements of supporting industrialization through savings mobilization, investment fund collections and maturity transformation and ensuring the environment of safe and efficient discharge the aforesaid functions. In most of emerging markets economic reform programs including liberalization, privatization and restructuring have not yet been completed or in the process of completion. In this case the knowledge of the prevailing relationship between stock prices and macroeconomic variables like consumption, investment, industrial production, GDP and the like, is predominantly important in the view of the fact that a stable relationship among these variables are likely to reform the important postulate in a variety of economic models.

Stock markets and capital markets act as a link between capital deficits and capital suppliers. Share prices signal the rate of return investors demand on securities of a particular risk class. If the market is inefficient the risk return relationship will be unreliable, Fama (1970), Jensen (1968) and Malkiel (1999).Stock markets may affect economic activity through the creation of liquidity. Stock markets also contribute to economic development by enhancing the liquidity of capital investments. On the other hand, the economic activity, capital investments (disinvestments) and monetary policy development may have long term effect on movement in stock prices which leads to increased (decreased) returns and risk premium demand on securities. Thus, this shows there is evidence that they may exist a bi- 
directional causality and long-run relationship between movement of stock prices and movement of macroeconomic variables in the real sector of the economy.

Based on the assumption of strong and persistent relationship between macro-economic variables and stock market prices and returns, several considerations have led to revisit the monetary development in Kenya in the recent two decades. Kenya experienced a significant macro-economic crisis which was associated with high inflation, loss of control of the money supply, the failure and/or distress of several banks and non-bank financial intermediaries and high interest rates which pushed many businesses into difficulties and generated a large non-performing portfolio. Also, major economic and financial reforms under the auspices of the IMF and WB as part of financial sector liberalization removed interest rates and exchange controls. Following the liberalization of the economy, financial disintermediation, rather than deepening occurred. However, in the context of an already poorly performing economy, lack of discipline in macroeconomic management and a weak banking system, the move to liberalize financial markets produced disappointing results.

The major initial public offers by various firms as equity financing in the mid-2000s lead to large shifts in liquidity, dip in stock prices while the 2008 post-election disturbances impact lead supply networks for food in most parts of the country leading to high inflation rates which had long-term impact on the economy and financial markets. The escalating oil prices, global economic crisis leading to weak consumer spending and the volatile foreign exchange rate resulting in the weakening of the shilling all combined to reduce the spending power of securities, other investments and drive away foreign investors.

\subsection{Statement of the Problem}

In the view of economic developments, it has become imperative to study the movements of stock returns as well as the numerous macroeconomic aggregates and indicators. This is because the stock market is the most sensitive segment of any developing economy. The macroeconomic events working on the investors' psychology affect their buy sell decision rules. This results in stock price volatility which in turn exerts influence on the macroeconomic aggregates. The crucial question here is how instantaneously this information are transmitted to the investors and market analysts at large and reflected in the stock prices. This brings up the issue of stock market efficiency. The interactions taking place over time, analysis of which necessitates a suitable time series analysis. The purpose of this research is to investigate the interaction between the stock price and a set of macroeconomic variables in the context of Kenyan economy from the period of $1980-2012$.

The analysis of the interrelationship runs in terms of Efficient Market Hypothesis. The Efficient Market Hypothesis (semi-strong form), states that in a semi strong efficient market, everyone has perfect knowledge of all publicly available information and these are fully reflected in stock prices otherwise, the market participants are able to develop profitable trading rules and the stock market will not channel financial resources to the most productive sectors.

Evaluating the relationship between macroeconomic variables and stock return is of crucial concern for an economy. Policy makers would wish to establish which variables to control and how to control them in order to create an enabling environment for thriving investments. There is therefore a need for an in-depth and an extensive evaluation of the relationship between stock returns and the macroeconomic variables. When markets are volatile the nature of informational flow from one market to the other across the globe is unprecedented, and the potential investors are wary to take risk as at this time, then there is a need to assess the long run relationship and causal linkage of these markets with some crucial macroeconomic variables as to ascertain their true status and provide the prospective investors with a consistent regulatory frame work.

\subsection{Objectives}

The general objective of this study was to analyze the relationship between selected macroeconomic variables and stock returns at the Nairobi Securities Exchange Limited.

The specific objectives of this study were to;

- To investigate the presence of causal relationship between stock prices and macroeconomic variables.

- To examine the direction of causal relationship between and stock market prices and macroeconomic variables (i.e. is it uni-directional or bidirectional).

\subsection{Research Hypotheses}

H01: There is no significant relationship between Real GDP and stock returns.

H02: There is no significant relationship between Broad money supply and stock returns.

H03: There is no significant relationship between Inflation rates and stock returns.

H04: There is no significant relationship between Interest rates and stock return.

\subsection{Scope of Study}

The study covered the period from the year 1980 to 2012 with annual data provide by the Kenya National Bureau of Statistics.

\subsection{Significance of the Study}

The significance of the study is as follows:

Academic expected gain is to add to the existing literature on the relationship between stock market returns and macroeconomic variables.

Policy makers, financial researchers and wary potential investors will be well informed on the status of the stock markets thereby monitoring the markets on a consistent regulatory frame work. 


\subsection{Limitations of the Study}

This study is only limited to secondary data which may in one or the other way lead to information which is not updated, hence inaccuracy may occur in analysis of data.

\subsection{Assumption}

Macroeconomic variables have similar impact on stock market returns depending on the trading mechanisms and regulatory environments.

NSE- 20 share index is used as a proxy for stock market performance to conduct the Granger causality test and verify the direction of causality.

\subsection{Definition of Terms}

Stock market: A market that deals with the exchange of securities issued by publicly quoted companies and the government.

Inflation: is the persistent increase in the price levels of goods and services over a given time period.

Stock Exchange: Organized and regulated financial market where securities (bonds, notes, shares) are bought and sold at prices governed by the forces demand and supply.

Stock Performance: It succinctly refers to how stocks fare under their respective markets given the risks and returns of the markets.

GDP: The money value of all goods and services produced within the country but excluding net income from abroad.

Stationary: Situation in which the mean variance and autocorrelation are constant over time in time series, that is, the statistical properties do not change with time.

\section{Literature Review}

\subsection{Introduction}

In this chapter a detailed literature review on causal relationship between stock returns and macroeconomic variables is given. The chapter is divided into two parts, theoretical Literature Review and Empirical Literature.

This chapter presents theoretical and empirical literature that aims at developing an understanding of the causal linkage between stock prices and selected macroeconomic variables in Kenya.

\subsection{Theoretical Literature Review}

After 1986, the relationship between macroeconomic variables and stock prices was extensively investigated. A brief overview of the studies using macroeconomic factors models is presented in this section. The findings of the literature suggest that a significant linkage exist between macroeconomic variables and stock prices in developed economies but such relationship does not exist in developing economies.

The linkage between Stock Market and the so called Macroeconomic variables has over the years, gained reasonable academic attention from students, researchers, stock brokers, to mention but a few. The earliest work of researchers in this area has been on different activities of the stock markets with response to either a single or two macroeconomic variables. Most of the findings as of that time were limited to stock markets microstructure neglecting other risk factors. For instance, Fisher (1930) hypothesizes equity stocks to represent claims against real asset of a business and infers that stock may serve as hedge against inflation. Mandelbrot (1963) and Fama (1965) report evidence of large changes of market stock price to be often followed by other large changes which explains cluster effect of the stock. Other pioneering research in this area include the work of Sharpe (1964), Lintner (1965), Modigliani and Cohn (1979), Nelson (1976), Fama and Schwert (1977),(Fama1981) and (Chen et al. 1986).Fama (1970) states that an ideal market is one in which prices provide accurate signals for resource allocation. He goes further to postulate that an efficient market is one in which prices always fully reflect available information. This is the central tenet of the Efficient Market Hypothesis ( EMH ).Fama (1970) also classifies three types of efficient markets, the weak form, semi strong and strong form. The weak form market reflects all past, publicly available information, while the semi strong form not only reflects available information, but also price change instantly to reflect new public information. The strong form market fully reflects all information, adjusts instantly to new information and even reflects hidden or "insider" information.

Monetary policy development has been the central debate in economics and finance as the influence of stock market development. Various studies and monetary condition in Kenya also have shown that there is a long-run significant effect and causality of monetary policy developments on stock returns. Many profitable investments require a longterm commitment of capital, but investors are often reluctant to relinquish control of their savings for long periods. Liquid equity markets make investment less risky and more attractive because they allow savers to acquire an asset or equity and to sell it quickly and cheaply if they need access to their savings or want to alter their portfolios. At the same time, companies enjoy permanent access to capital raised through equity issues.

Under arbitrage pricing asset (APT) Chen, Roll and Ross (1986) identified the following macroeconomic factors such as surprises in inflation, GNP, yield curve and investor confidence as significant in explaining security returns .In addition their impact on asset prices manifests in their unexpected movements which should represent undiversifiable influences (these are, clearly, more likely to be macroeconomic rather than firm specific in nature), timely and accurate information on these variables is required and the relationship should be theoretically justifiable on economic grounds. This theory can be supported by efficient market hypothesis (EMH) championed by Fama (1970) in particular with semi-strong form efficiency which states that stock prices must contain all relevant information including publicly available information has important implications for 
policy makers and the stock broking industry alike. As for the effect, macroeconomic variables such as money supply and interest rates on stock prices, the efficient market hypothesis suggests that competition among the profit maximizing investors in an efficient market will ensure that all relevant information currently known about changes in macroeconomic variables are fully reflected in current stock prices, so that investors will not be able to earn abnormal profits through prediction of future stock market movements.

\subsection{Empirical Literature Review}

A number of studies have used different techniques to estimate the relationship between macroeconomic variables and stock market prices. In Kenyan studies, Ochieng and Oriwo (2012) on study of effect of macroeconomic factors (lending interest rate, inflation rate and 91-day T-bill rate on stock prices from 2008 to 2012 found that that 91-day T-bill rate has a negative relationship with the NASI while inflation has a weak positive relationship with the NASI. Contrary to this study, Muthike and Sakwa (2011) did a study on can indicators be used as predictors of the stock exchange index trends" and found that treasury bills, money supply, and real exchange rates were positive, while the signs of inflation rates and GDP were negative. The 91-day T-bill rate and the inflation rate were the only clear leading macroeconomic indicators on the NSE-20 Index.

The study concluded that the Kenyan stock market formed significant relationships with all macroeconomic indicators identified, except the gross domestic product. Studies on causality relationship centered on the question of whether there is long-run effect and relationship between macroeconomic variables and stock prices. Olweny and Kimani (2011) found that the causality between economic growth and stock market runs unilaterally or entirely in one direction from the NSE 20-share index to the GDP. From the results, it was inferred that the movement of stock prices in the Nairobi Securities Exchange reflect the macroeconomic condition of the country and can therefore be used to predict the future path of economic growth whilst Kisaka and Mwasaru (2012), their empirical results indicate that exchange rates Granger-causes stock prices in Kenya.

In other economies, Vuyyuri (2005) investigated the cointegrating relationship and the causality between the financial and the real sectors of the Indian economy using monthly observations from 1992 to 2002, the financial variables used were interest rates, inflation rate, exchange rate, stock returns and real sector was proxied by industrial productivity employing Johansen (1988) multivariate cointegration test supported the long-run equilibrium relationship between financial sector and the Granger causality test showed unidirectional causality between the financial sector and real sector of the economy. Maghyerch (2002) investigated the long-run relationship between the Jordanian stock prices and selected macroeconomic variables again using Johansen (1988) cointegration analysis and monthly time series data for the period from 1987 to 2000 . The study showed that macroeconomic variables were reflected in stock prices in the Jordanian capital market. Orman (2003) focused on examining the impact of real interest rates as key factor on the performance of Egyptian stock market both in terms of market activity and liquidity. The cointegration analysis through Error correction mechanism (ECM) indicated significant long-run and shortrun relationship between the variables implying that real interest rates had an impact upon stock market performance.

Chen et al. (1986) examined equity returns relative to a set of macroeconomic variables and found that the set of macroeconomic variables which can significantly explain sock returns includes growth in industrial production, changes in the risk premium, twists in the yield curve, measures of unanticipated inflation and changes in expected inflation during periods of volatile inflation. More recent examples of studies involving a number of macroeconomic variables include Chen (1991), and Flanery and Protopapadakis (2002). Some studies also find that the predictive ability of certain macroeconomic variables with respect to stock returns is quite uneven over time. On the other hand, there is no dearth of studies, which fail to support the ability of macro variables to predict stock returns.

Another study conducted by Sarkar, P. (2005) has examined that if any meaningful relation between growth and capital accumulation exists in case of India. They have used annual data on various variables like nominal and real share price, share market turnover ratio, number of listed firms in the stock market, fixed capital formation and growth of real GDP and industrial output. But all tell the same story that no positive relationship exists between real and stock market variables either in short run or long run during 1950 to 2005.

Kanakaraj et al. (2008) have examined the trend of stock prices and various macro-economic variables between the time periods 1997-2007. They have tried to explore upon and answer that if the recent stock market boom can be explained in the terms of macroeconomic fundamentals and have concluded by recommending a strong relationship between the two. The GDP growth in India has grown consistently at high levels touching the highest average from 2003-04 to 2006-07 since Independence, and is strongly backed by manufacturing sector growth and services sector growth. Gross Domestic Investment and Gross Domestic Saving as percentage of GDP have also grown enormously with inflation remaining under control most of the time.

Muhammad and Rasheed (2002) examined the exchange rates and stock price relationships for Pakistan, India, Bangladesh and Sri Lanka using monthly data from 1994 to 2000. The empirical results showed that there is a bidirectional long-run causality between these variables for only Bangladesh and Sri Lanka. No associations between exchange rates and stock prices were found for Pakistan and India.

Abdalla and Murinde (1997) found out that the results for India, Korea and Pakistan suggest that exchange rates Granger cause stock prices, which is consistent with earlier study by Aggarwal (1981). But, for the Philippines, Abdalla and Murinde found out that the stock prices lead the 
exchange rates. This is consistent with Smith's (1992) finding that stock returns have a significant influence on exchange rate in Germany, Japan and the United States.

Dasgupta (2012) using the Johansen and Juselius's cointegration test find the Indian stock markets to be cointegrated with macroeconomic variables. In the long-run, the stock prices are found to be positively related to interest rate and industrial production while the wholesale price index used as a proxy for inflation and the exchange rate are negatively related to Indian stock market return. The findings however fail to establish short-run relationships between the Indian stock market and the macroeconomic variables.

Yusof et al. (2006) employ the autoregressive distributed lag model (ARDL) to examine the long run relationship between macroeconomic variables and stock returns in Malaysia. The macroeconomic variables tested in the study are the money supply, industrial production index, real effective exchange rate, and Treasury bill rates. As hypothesized, money supply is found to be positively related to the changes in stock prices while exchange rate has negative effect on stock prices in the Malaysian market. Khalid (2012) using Granger causality test establishes unidirectional causality running from exchange rate to stock performance on the Karachi Stock Exchange return.

\subsection{Conceptual Framework}

This is an analytical tool with several variations and contexts. It is used to make conceptual distinctions and organize ideas. Strong conceptual frameworks capture something real and do this in a way that is easy to remember and apply. Likewise conceptual frameworks are abstract representations, connected to the research project's goals that direct the collection and analysis of data. The conceptual framework as brought out from the literature review in this study is illustrated in the figure below.
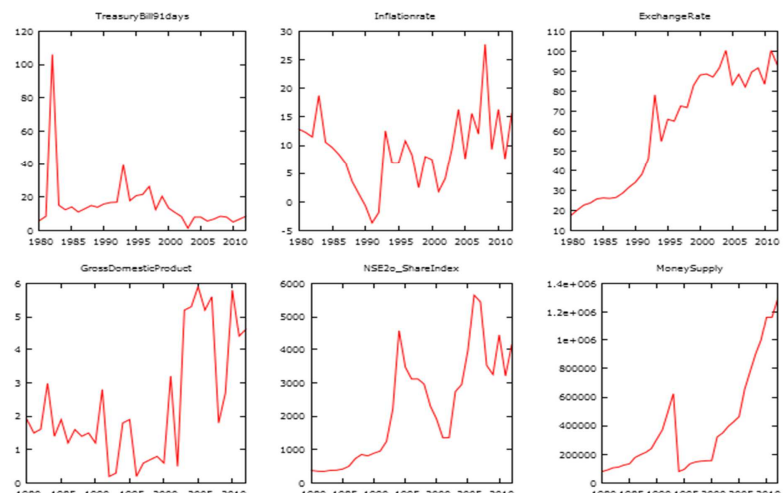

Figure 1. Conceptual Framework.

\subsubsection{Independent Variable}

These are variables that influence the dependent variable in either positive or negative way. Meaning that, the variance of a dependent variable is accounted for by the independent variables therefore, giving a causal relationship between the two variables. For instance, exchange rates, broad money supply, Treasury bill rate, inflation and gross domestic product are independent variables influencing stock return which is a dependent variable.

\subsubsection{Dependent Variable}

It is a variable of primary interest to the researcher. Through analysis of dependent variable; it is possible to find solutions to the problem. A stock return is the dependent variable and it is influenced by the above mentioned independent variables.

\subsubsection{Moderating Variables}

They have contingent effect on the relationships between independent and dependent variables. The presence of moderating variables modifies the relationships between independent and dependent variable. Foreign direct investment, fiscal and monetary policies are the moderating variables modifying the relationships between the mentioned independent variables and dependent variable (Stock market returns).

\section{Research Methodology}

\subsection{Research Design}

This study adopts a causal relationship research design to investigate the causal relationship between the stock market performance and macroeconomic variables in Kenya. This enables the researcher to understand how one variable under study affected, or was responsible for changes in another variable. Causal research design was chosen because in business research, the cause-effect relationship is less explicit. Cooper et al. pointed out that, use of a causal research design eases the understanding, explanation, prediction and control of any relationship between variables under study.

\subsection{Site of the Study}

The location of study was Kenya. Kenya is a country found in the Eastern part of the Africa continent .Its among Eastern African countries that include Uganda, Tanzania, Somalia, Ethiopia, Southern Sudan, Rwanda and Burundi.

\subsection{Target Population}

The population of this study was all quoted companies at the Nairobi stock exchange. On the other hand, the performance of the overall economy was targeted and measured by the changes in real GDP, inflation rates, interest rates and the broad money supply.

\subsection{Sampling and Sample Design}

This study utilized a purposive sampling by employing the most recent data series on the variables under investigation to meet the objectives of the study.

\subsection{Instrumentation}

Othman Ismail (2010) defines instrumentation as the use of various survey instruments or questionnaire. Some of these survey instruments can readily be obtained from 
professional organizations. Survey instruments on aptitude, perception, motivation, interest, attitude and many others have been carefully designed, evaluated for validity and reliability, piloted and even administered successfully before they are made available for other researchers to embark on.

\subsubsection{Reliability}

According to Mugenda et al., reliability is the degree to which a measure is consistent in producing the same reading or results when measuring the same thing at different times. Reliability is influenced by random error, that is, as random error increases, reliability decreases. The random error is the deviation from the true measurement due to the factors that have not effectively been addressed by the researcher. The notable sources of errors are inaccurate coding, ambiguous instructions to the subjects, interviewer and interviewee fatigue. This study assumed the secondary data provided by the Kenya National Bureau of Statistics was reliable.

\subsubsection{Validity}

There is no specific statistical method to calculate validity since it is the ability of the instrument to measure what it is intended to measure (Omondi, 2007). According to Mugenda et al., validity is the accuracy and meaningfulness of inferences which is made on the research results. If data is a true reflection of the variables, then inferences based on such data will be accurate and meaningful. Validity is largely determined by the presence or absence of systematic error (nonrandom error) in data. An instrument can yield reliable data that are not necessarily valid because reliability is determined by random error which contradicts validity determination. To enhance face validity of the results, the researcher consulted the supervisors and other expert readers for validation of research instruments. The supervisors and other expert readers were fundamental in the corrections and authentication of the instruments for final use in the study.

\subsection{Data Collection}

In order to fulfill the objectives of this study, a data collection guide was used to capture the required data. The study wholly depended on the use of annual secondary data from the year 1980 to 2012 on Stock market performance and macroeconomic variables due to non-availability of reliable data on the stock market before 1979. The NSE 20-share index was chosen as a proxy for the stock market because it is able to measure price movements in selected, relatively stable and best performing 20 listed companies at the bourse. Another benefit of the index was that it is based on a geometric mean of average prices of the constituent companies which are equally weighted, and that it is reviewed periodically to ensure that it reflects an accurate picture of market performance. GDP, Treasury Bill Rates, inflation rate and broad money supply were picked as the preferred macroeconomic indicators because they are widely used by economists and policy makers alike to gauge the health of an economy, and on this account their variations are also relatively and quickly identified. The GDP, Treasury Bill
Rates, inflation rates and broad money supply (M3) were collected from published economic reports, the annual Statistical abstracts published by the Kenya National Bureau of Statistics. On the other hand, the NSE 20-share index was obtained from the Nairobi stock exchange.

\subsection{Data Processing and Pre-estimation Diagnostics}

The data used in this study was in logged form, and hence changed in to natural logarithms in order to improve its interpretability, and consequently the statistical analysis.

\subsubsection{Test for Stationarity}

In order to avoid the possibility of biased results emanating from a likely existence of unit roots in the variables under study, the researcher performed stationarity test using the ADF (Augmented Dickey Fuller) test procedure.

\subsubsection{Testing for Cointegration}

To perform this, the Johansen-Juselius test procedure was used to test for the possibility of a long-run equilibrium relationship among the variable under Tobias Olweny and Danson Kimani examination. This way, the researcher was able to analyze whether the time series under study share a common stochastic drift or not.

\subsubsection{Testing for the Causality}

The Granger-causality test was also used to investigate direction of causation between stock market performance and macroeconomic variables. The outcome from the Grangercausality test was used to determine whether the variables under study can be used to predict each other or not. At the same time, the variables used in the granger-causality test were all assumed to be stationary i.e. I (0) process.

\subsubsection{OLS Regression Analysis}

OLS Regression analysis was used to investigate the impact of stock market performance on the selected macroeconomic variables. The test also used Durbin Watson ' $d$ ' statistic to test for serial autocorrelation and Adjusted RSquared to test for goodness of fit of the model.

\subsection{Model Specification}

The study employed a vector autoregressive (VAR) model to estimate and provide empirical evidence on the nature of causal relationship between the NSE 20-share index and changes in macroeconomic variables. The VAR model provided a systematic way to capture rich dynamics between the variables under study. Sim et al. (1973) argued that VAR held out the promise of providing a coherent and credible approach to data description, forecasting, structural inference and policy analysis. VARs has proven to be powerful and reliable tool because VARs involve current and lagged values of multiple time series, and their ability to capture comovements that cannot be detected in univariate or bivariate models. Furthermore, standard VAR summary statistics like Granger-causality test and variance decompositions are wellaccepted and widely used methods for portraying these co- 
movements.

In Granger causality test, the study employs Sim's (1972) test based on Granger's (1969) definition of causality. Granger causality statistics examines whether lagged values of macroeconomic variables help predict stock prices in Kenya. For this case, a bi-variate model is formed by these two equations ( 1 and 2 ).

$$
\begin{gathered}
L N S E_{\mathrm{t}}=\alpha_{10}+\alpha_{11} \mathrm{LNSE}_{\mathrm{t}-\mathrm{j}}+\alpha_{12} \mathrm{MACR}_{\mathrm{t}-\mathrm{j}}+\mathrm{e}_{1 \mathrm{t}} \ldots \\
\mathrm{LMACR}_{\mathrm{t}}=\alpha_{20}+\alpha_{21} \mathrm{LNSE}_{\mathrm{t}-\mathrm{j}}+\alpha_{22} \mathrm{LMACR}_{\mathrm{t}-\mathrm{j}}+\mathrm{e}_{2 \mathrm{t} .} \ldots
\end{gathered}
$$

According to Granger's definition of causal relationships:

$$
\begin{aligned}
& \text { NSE does not cause MACR, if } \alpha_{11}=\alpha_{12}=0 \\
& \text { MACR does not cause NSE, if } \alpha_{21}=\alpha_{22}=0
\end{aligned}
$$

In order to judge whether these conditions hold, Sim's employ the following F-statistic to be applied to equations (3) and (4). With Sim's test, the result of F-test direction of causality is judged as follows;

(i) Equation (3) holds, equation (4) does not hold; MACR causes NSE (MACRNSE).

(ii) Equation (3) does not hold, equation (4) holds; NSE causes MACR (NSEMACR).

(iii) Both (3) and (4) hold; Feedback between MACR and NSE (MACRNSE).

(iv) Neither (3) nor (4) holds; MACR and NSE are independent.

However, results from VAR model are sensitive to the lag length since the direction of causality may depend critically on the number of lagged terms included in the model and the fact that in an $m$ variable, VAR models all the $m$ variables should be stationary. This study used Akaike information criterion (AIC) and Schwarz information criterion (SIC) to determine the option lag length then chose model that gives the lowest values of these criteria, that is, including too many lagged terms consumes the degree of freedom while including too few lags leads to model specification errors.

\subsection{Data Analysis}

The analysis used secondary time series data of period from 1980 to 2012. NSE-20 index is used as the proxy for the performance of the Nairobi Securities Exchange and stock price in Kenya. Five macroeconomic variables are used namely, real GDP, Treasury bill rate, inflation rate, foreign exchange rate and broad money supply (M3). The data was obtained from Central Bank of Kenya annual publications and Kenya National Bureau of Statistics annual economic surveys. The priori expectations of the five macroeconomic variables are hypothesized as; there exist a positive relationship between real GDP, broad money supply (M3) and stock prices whilst there exist a negative relationship between Treasury bill rate (TBR), inflation rate (INF), foreign exchange rate (EXR) and stock prices.

\section{Data Compilation, Analysis and Presentation}

\subsection{Introduction}

This chapter presents the results of all econometric tests conducted by the study as well as regression results. The estimation of the model and other diagnostic tests are done using Gretl and R GUI. First descriptive statistics was used to view the overall structure of the variables in question. The unit root tests are conducted in order to identify the time series characteristics of the variables and finally the Ordinary Least Squares method was used to test the significance relationship between the variables as well as cointegration relationship for our model and Granger causality test performed on the variables aforementioned.

\subsection{Descriptive Statistics}

The summary statistics for NSE20-Share Index, inflation, exchange rates, money supply, Treasury bill rate and GDP are given in Table-1.The mean of NSE20-Share Index is 2308.86. The mean of the inflation is 9.06559. The one for exchange rate is 62.4338, Treasury Bill Rate is 15.6862 ,moey supply is 425700 ; and the mean of the Gross Domestic Product is 2.42324.The kurtosis for all the aforementioned factors is less than 3, i.e. the frequency

\begin{tabular}{|c|c|c|c|c|}
\hline Variable & Mean & Median & Minimum & Maximum \\
\hline NSE20_ShareInde & 2308.86 & 2255.15 & 350.310 & 5646.00 \\
\hline TreasuryBill91d & 15.6862 & 12.5300 & 1.41000 & 106.000 \\
\hline Inflation rate & 9.06559 & 8.85000 & -3.66000 & 27.7000 \\
\hline money supply & 425700 . & 274617 . & 81040.1 & $1.36079 \mathrm{e}+006$ \\
\hline RealExchangeRate & 62.4338 & 72.2300 & 17.5700 & 100.390 \\
\hline GrossDomesticPr & 2.42324 & 1.80000 & 0.200000 & 5.90000 \\
\hline Variable & Std. Dev. & C.V. & Skewness & Ex. Kurtosis \\
\hline TreasuryBill91d & 17.4880 & 1.11487 & 4.26054 & 19.3537 \\
\hline Inflation rate & 6.28931 & 0.693756 & 0.390009 & 0.957418 \\
\hline money supply & 386113. & 0.907008 & 1.17422 & 0.107917 \\
\hline RealExchangeRate & 29.1862 & 0.467473 & -0.287647 & -1.57995 \\
\hline GrossDomesticPr & 1.82526 & 0.753233 & 0.673343 & -0.913532 \\
\hline
\end{tabular}
distribution assigns a lower probability to returns around zero as well as very low positive and negative returns.

Table 1. Descriptive Statistics.

Summary Statistics, using the observations 1980 - 2012 


\subsection{Stationarity Test}

Most macroeconomic time series data are often assumed to be non-stationary and thus it is necessary to perform a pretest to ensure there is a stationary to avoid the problem of spurious regression. Table 1 presents the ADF unit root test at their levels, which clearly shows that the null hypothesis of the existence of a unit root is rejected at 5\% significance levels. Hence, all the series are accepted not to contain unit root.

Table 2. Unit Root Test.

\begin{tabular}{lll}
\hline ADF Unit Root Test & & \\
\hline Variables & Intercept & Trend and Intercept \\
LNSE & $-3.809774(0.0003)$ & $-3.812799(0.0003)^{*}$ \\
LGDP & $-8.326202(0.0000)$ & $-8.472317(0.0000)$ \\
LEXR & $-5.689688(0.0000)$ & $-5.712849(0.0000)$ \\
LINF & $-3.540389(0.0008)^{*}$ & $-3.508139(0.0009)^{*}$ \\
LTBR & $-5.554974(0.0000)$ & $-5.585226(0.0000)$ \\
LMS3 & $-8.162753(0.0000)$ & $-8.1067410(0.0000)$ \\
\hline
\end{tabular}

* denotes rejection of the hypothesis at the 0.05 level
Results in Table 2 above show that the ADF p-values are less than the level of significance $(\alpha=0.05)$ and we therefore reject the null hypothesis of non-stationarity and accept that the series are stationary.

\subsection{Cointegration}

The cointegration tests are undertaken based on the Johansen and Juselius (1990) maximum likelihood framework. The aim was to determine whether there exists a cointegrating vector between stock market price (NSE-20 Index) and the five macroeconomic variables (real GDP, 91day Treasury Bill Rate, inflation rate, foreign exchange rate and broad money supply). Table 2 presents the Johansen cointegration test results. Note that, since the trace statistics takes into account, all of the smallest Eigen values, it possesses more power than the maximal Eigen value statistic. Furthermore, Johansen and Juselius (1990) recommend the use of the trace statistics when there is a conflict between the two statistics.

Table 3. Johansen Cointegration Test Results: 1 to 1.

\begin{tabular}{lllll}
\hline Eigen Values & Likelihood Ratio (Trace statistic) & $\mathbf{5 \%}$ Critical value & 1\% Critical value & Hypothesized No. of CE(s) \\
\hline 0.440320 & 92.84143 & 94.15 & 103.18 & None \\
0.338052 & 58.01802 & 68.52 & 76.07 & At most 1 \\
0.251567 & 33.26391 & 47.21 & 54.46 & At most 2 \\
0.153716 & 15.87751 & 29.68 & 35.65 & At most 3 \\
0.093069 & 5.863490 & 15.41 & 20.04 & At most 4 \\
$3.54 \mathrm{E}-05$ & 0.002124 & 3.76 & 6.65 & At most 5 \\
\hline
\end{tabular}

* denotes rejection of the hypothesis at the 0.05 level

The trace statistics for the model are presented in Table 3. The trace statistics indicates that there are cointegrating equations. Therefore, the existence of cointegration is indicative of a long-run relationship between stock prices and macroeconomic variables.

\subsection{OLS Regression Analysis}

In order to examine the impact of stock market on the selected macroeconomic variables regression analysis was carried out at a significance level of $5 \%$. A summary of the output is given in Table 4 below.

Table 4. OLS, using observations 1980-2012 $(T=33)$.

\begin{tabular}{lllll}
\hline & Coefficient & std. error & t-ratio & p-value \\
\hline Const & -615.158 & 564.574 & -1.090 & 0.2855 \\
TreasuryBill91 days & 0.344502 & 11.3185 & 0.03044 & 0.0475 \\
Inflation rate & 26.4577 & 31.7274 & 0.8339 & 0.0411 \\
Exchange Rate & 33.6263 & 8.26568 & 4.068 & 0.0004 \\
GrossDomesticPr & 207.188 & 130.327 & 1.590 & 0.1235 \\
Money Supply & 0.000141579 & 0.000745491 & 0.1899 & 0.0408 \\
Mean dependent var & 2240.377 & S.D. dependent var & & 1607.233 \\
Sum squared resid & 29807395 & S.E. of regression & & 1050.703 \\
R-squared & 0.639408 & Adjusted R-squared & & 0.572632 \\
F (5, 27) & 9.575373 & P-value (F) & & 0.000024 \\
Log-likelihood & -273.1020 & Akaike criterion & & 558.2040 \\
Schwarz criterion & 567.1831 & Hannan-Quinn & & 561.2252 \\
Rho & 0.545016 & Durbin-Watson & & \\
\hline
\end{tabular}

Dependent variable: NSE2o_ShareIndex

Source : Researcher

The Adjusted R- Squared (0.572) is fairly impressive. It implies that $57.2 \%$ of the variations in stock prices are 
explained by the selected macroeconomic variables. The pvalues for the macroeconomic variables also indicate a significant relationship between stock prices with money supply, inflation rate, Treasury Bill Rate and exchange rate .In the above cases the null hypothesis of no significant relationship was rejected since the p-values were less than $5 \%$ level of significance. However GDP had an insignificant relationship with stock prices. The Durbin Watson'd' statistics of 0.906 also indicates that there was no serial autocorrelation.

\subsection{Granger Causality Test}

A test for existence and direction of Granger causality between the stock prices and

macroeconomic variables were carried out. Table 5 presents the results of Granger causality

test between the stock market prices and macroeconomic variables.

Table 5. Granger Causality test coefficients result.

\begin{tabular}{lll}
\hline Pair wise Granger Causality Tests & & \\
\hline Null Hypothesis: & F-Statistic & Prob. \\
LINF does not Granger Cause LNSE & 3.19087 & 0.0434 \\
LNSE does not Granger Cause LINF & 0.12721 & 0.8806 \\
LEXR does not Granger Cause LNSE & 2.93260 & 0.0357 \\
LNSE does not Granger Cause LEXR & 1.96838 & 0.1426 \\
LMS does not Granger Cause LNSE & 1.95224 & 0.1449 \\
LNSE does not Granger Cause LMS & 8.52446 & 0.0003 \\
LTBR does not Granger Cause LNSE & 0.56217 & 0.5709 \\
LNSE does not Granger Cause LTBR & 3.53757 & 0.0311 \\
LNSE does not Granger Cause LGDP & 6.32159 & 0.5419 \\
LGDP does Granger Cause LNSE & 4.6795 & 0.6432 \\
\hline
\end{tabular}

Effective Sample: 1980 - 2012.

The null hypothesis show that LNSE does not Granger cause LMACR except for Treasury Bill Rate and cannot be rejected neither the hypothesis that LMACR does not Granger cause LNSE except for inflation rate and exchange rate on stock prices because of the significant F-statistic ratio. Therefore, the Granger causality test results are described as follows, a change in the macroeconomic variables with except for inflation rate and exchange rate had a statistically insignificant impact on changes in the stock prices whilst changes in stock prices except for Treasury Bill Rates also seem to be an insignificant factor explaining part of the movements in the macroeconomic variables. This suggests that there is unidirectional causality from inflation rate, exchange rate to stock prices and also unidirectional causality from stock prices to Treasury Bill Rates.

\section{Summary, Conclusion, Recommendations and Suggestions for Further Research}

\subsection{Introduction}

This chapter presents the summary of the study findings, draws conclusions from the findings and provides recommendations for consideration and for further studies on the causal linkage between stock market returns and macroeconomic variables in Kenya.

\subsection{Summary}

The main objective was to investigate causal relationship between macroeconomic variables and stock prices empirically using secondary time series data from 1980 to
2012. Ordinary Least Square method was used to capture the relationship and the effect of macroeconomic variables on stock prices in Kenya and was found to be insignificant except for inflation rate, exchange rate and Treasury Bill Rates. These results were also consistent with the results of Granger causality test suggesting that stock prices does not Granger cause macroeconomic variables except for Treasury Bill Rates and macroeconomic variables does not Granger cause the stock prices with exception of inflation rate and exchange rate. That is, there is unidirectional causality from inflation rate, exchange rate to stock prices and also there is unidirectional causality from stock prices to Treasury Bill Rates. These findings exhibit mixed results in Kenya, for example, consistent results are found only in causality between exchange rate and stock prices of Kisaka and Mwasaru (2012), while others were inconsistent, Olweny and Kimani (2011). With other past studies that detect no evidence of causality between stock market prices and macroeconomic variables for example, Maghyerch (2002), Orman (2003), Vuyyuri (2005) where the association between the two variables has been found to be insignificant and there is long-run equilibrium.

\subsection{Conclusion}

These findings suggest the existence of arbitrage profit opportunities on the Nairobi stock market lending credence to the non-portability of the EMH. Based on past values of exchange rate, inflation and money supply, financial analysts can predict stock returns to make abnormal profit. We advise both current and potential investors to pay close attention to the movements of macroeconomic variables such as inflation, money supply and real GDP since they impact on the 
performance of their investments in the long-run. In the short-run, investors should closely monitor changes in interest rate, inflation and money supply. We further recommend to the managers of the economy to implement inflation and exchange rate policies that are conducive to the development of the capital market since our study provides evidence to show that changes in inflation and exchange rate elicit movements in the stock market which consequently causes a movement in the Treasury Bill Rate.

\subsection{Policy Recommendations}

The research analysis applied to the sample data found no consistent evidence that changes or movement in some macroeconomic variables impact on stock prices. There seem to be unidirectional flow of causality between the some macroeconomic variables and stock prices in Kenya. According to the findings the insignificant effect on movement of stock prices shows that policies aiming at stabilizing macroeconomic variables will have a delayed effect on stock prices, but this effect is significant. Therefore, an important recommendation of the analysis for the conduct of effective monetary policy in Kenya is that attention should be given to the complementary and coordinated development of financial reforms and changes in the monetary sector of the economy. The government should make necessary reforms for a well-developed monetary sector which can foster stock market in the long-run. Also, issues such as promoting the right political climate, improving macroeconomic stability, professionalization of asset management business and privatization of the management of public funds. It also provides support to theories according to which well-functioning financial sector and money market can promote stock market by fueling the engine of economic growth through faster capital accumulation and by tuning it through better investment opportunities. That is, better money market can give a big boost to stock market development.

\subsection{Suggestion for Further Studies}

This study should not be taken as being conclusive but there is need for future studies on the following areas:-

- i. Carry out further research on the same topic using larger samples.

- ii. Carry out a similar study to the current one but including other macroeconomic variables and nonmacroeconomic variables.

- $\quad$ iv. A study to investigate the relationship between stock market returns and macroeconomic variables using alternative methodologies.

- $\quad$ v. A similar study is recommended using daily or weekly data to assess whether the relationship between stock market returns and macroeconomic variables is sensitive to the frequency of data.appendices
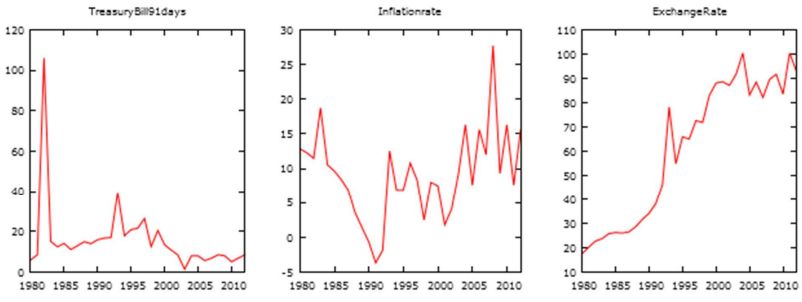

Grossomestichooued

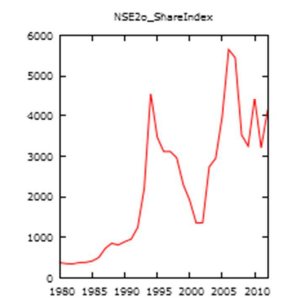

Moreysuppiy
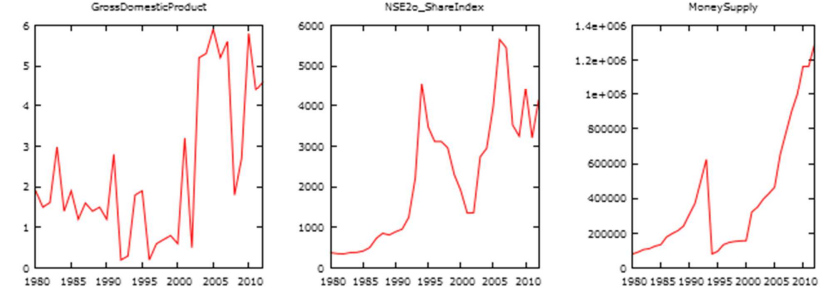

Figure 2. Variation of Stock Price and Selected Macroeconomic Variables with Time.

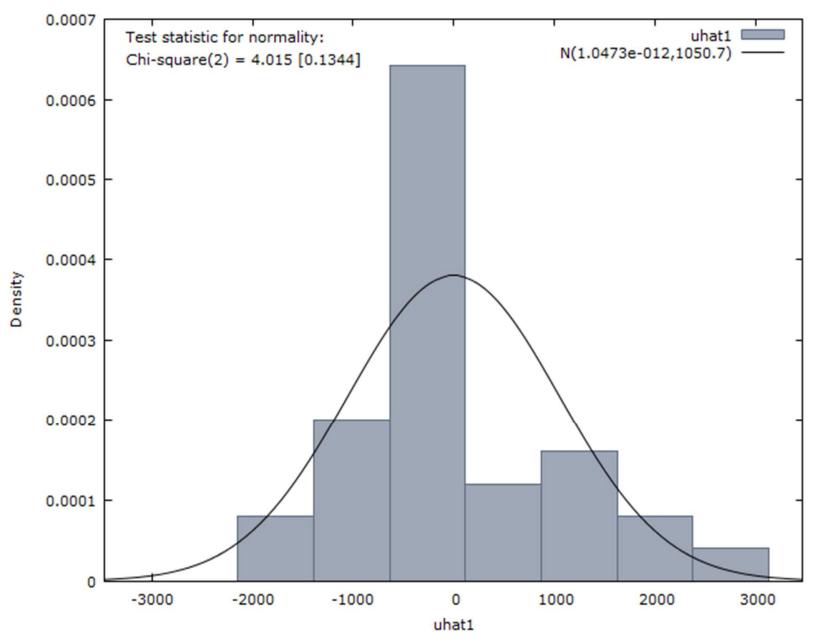

Figure 3. Normality Test Using Frequency Distribution.

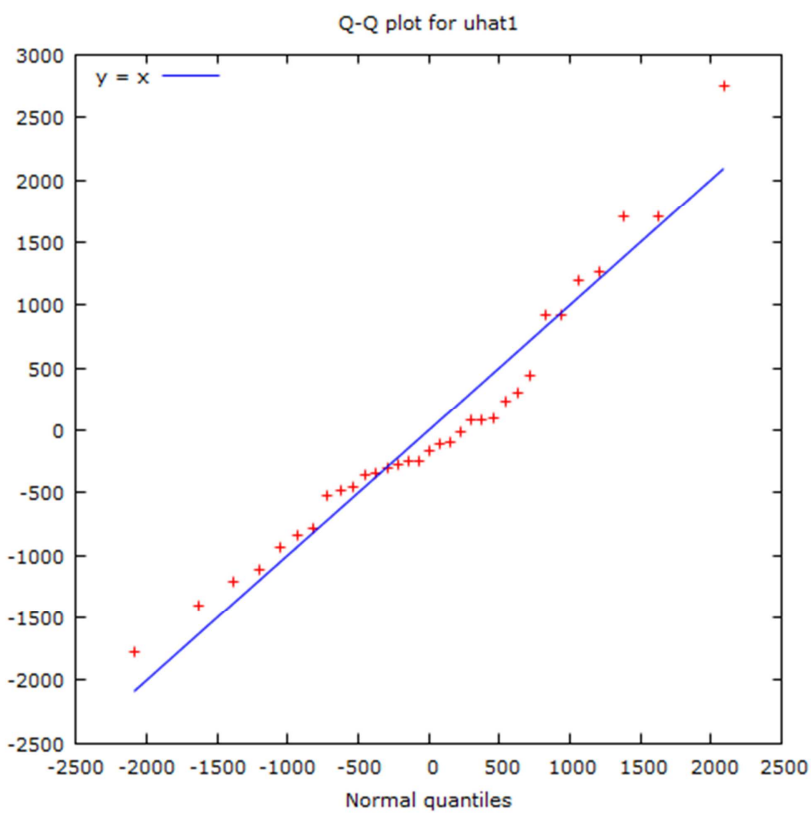

Figure 4. Normal Q-Q Plot for Normality Test. 


\section{References}

[1] Chen, N.-F. \&. (A.S 1986). Economic Forces and the Stock Market. Journal of Business , 383 - 403.

[2] Ehrmann, M. \&. (2004). Talking Stock Monetary Policy Transmission to Equity Markets. Credit and Banking, 719-37.

[3] Fama, F. (1970). Efficient Capital Markets: A Review of Theory and Empirical Work. Journal of Finance , 25, 383-417.

[4] Granger, C. (1969). Investigating Causal Relations by Econometric Models and Cross Spectral Methods (Vol. 37).

[5] Jensen, M. (1969). The Performance of Mutual Funds in the Period 1945-1964. Journal of Finance 23 , 389-416.

[6] Johansen, S. \&. (1990). Maximum Likelihood Estimation and Inference on Cointegration with Applications to the Demand for Money. (Vol. 52). Oxford Bull. Econ. Stat.

[7] Johansen, S. (1986). Statistical Analysis of Cointegration Vectors. Journal of Economic Dynamics and Control , 389416.

[8] Kisaka, S. \&. The Causal Relationship between Exchange Rates and Stock Prices in Kenya. Journal of Finance and Accounting, 3 .

[9] Kovačić, Z. J. Forecasting Volatility: Evidence from the Macedonian Stock Exchange. International Research Journal of Finance and Economics (18 (2008)), ISSN 1450-2887.

[10] Maghyereh, A. I. (2002). Causal Relations Among Stock Prices and Macroeconomic Variables in the Small, Open Economy of Jordan.

[11] Malkiel, B. (1999). A Random Walk Down Wall Street. New York: Norton \& Co.

[12] Muthike S.W \& Sakwa, M. M. (2011). Can Macroeconomic Indicators be used as Predictors of the Stock Exchange Index Trends? A Look at the Nairobi Stock Exchange. Nairobi: Jomo Kenyatta University of Agriculture and Technology.

[13] Ochieng D. E. \& Oriwo, A. E. (2012). The Relationship Between Macroeconomic Variables And Stock Market Performance In Kenya (Vol. 1). DBA Africa Management Review 2012.

[14] Olweny, T. O. (2011). Stock market and Economic Growth, Empirical Evidence from Kenya using Causality Test Approach. Advances in Management \& Applied Economics, 1.

[15] Omran, M. (2003). Time Series Analysis of the Impact of Real Interest Rates on Stock Market Activity and Liquidity in Egypt. Co-integration and Error Correction Model Approach. International Journal of Business 8(3). , 8 .

[16] Porteba, J. \&. (1986). The Persistence of Volatility and Stock Market Fluctuations, American Economic Review.

[17] Sims, C. A. (1972). Money, Income and Causality. American Economic Review, pp. 540-552.

[18] Vuyyuri, S. (2005). Relationship between Real and Financial Variables in India: A Cointegration Analysis. 